\title{
Uso propagandístico del concepto "patria" en el gobierno de Rafael Correa. Análisis de dos spots electorales de 2009 y 2013
}

\section{Political advertising usage of the concept "homeland" in the government of Rafael Correa. Analysis of two electoral spots of 2009 and 2013}

DOI: https://doi.org/10.29166/tyc.v1i19.2075

\section{María Elena Pérez}

Es graduada de la Pontificia Universidad Católica del Ecuador, como Licenciada en Comunicación Organizacional. Posteriormente, realizó sus estudios de maestría en la Universidad de Sevilla (España) sobre Comunicación y Cultura. Cuenta con experiencia en desarrollo de estrategias de comunicación, relaciones públicas y corrección de textos académicos y educativos.

Correo:meperezd@gmail.com

\section{Resumen}

Este estudio pretende comprender la utilización que el ahora expresidente de la República del Ecuador, Rafael Correa, hizo del término "patria" en su propaganda electoral. Para ello, se toma un spot de su candidatura presidencial de 2006 y otro de 2013 como objetos de análisis. Aunque existen numerosos estudios sobre la propaganda de Correa, no hemos encontrado ninguno que se haya centrado en el uso del concepto "patria", por lo que esta investigación puede ser útil para futuros acercamientos. Tras el análisis, observamos que el concepto central de la propaganda de Correa es justamente la patria y que, a partir de su uso propagandístico, el entonces presidente busca modificar algunos elementos de los imaginarios colectivos preexistentes, así como sustituirlos por otros más acordes con su ideología.

Palabras clave: Rafael Correa, Ecuador, propaganda política, comunicación, patria, spots electorales.

\section{Abstract}

This study aims to understand the use that the now former president of Ecuador, Rafael Correa, made of the term "homeland" in his electoral publicity. To do this, a spot is taken from his 2006 presidential candidacy and another from 2013 as objects of analysis. Although there are numerous studies on the Correa's advertising we have not found any that have focused on the use of the concept "homeland", so this research may be useful for future approaches. After the analysis, we observe that the central concept of Correa's propaganda is precisely the homeland and that, from its advertising usage, the president seeks to modify some elements of the preexisting collective imaginary, as well as replace them with others more in line with his ideology.

Keywords: Rafael Correa, Ecuador, political advertising, communication, homeland, electoral spots. 


\section{Introducción}

En mayo de 2017, Rafael Correa salía de la presidencia de Ecuador después de más de 10 años de mandato que dejaron a pocos indiferentes. En efecto, el proyecto político que ilusionó a muchos en el país se vio acompañado de la imagen mediática de un líder carismático con incuestionables dotes persuasivos.

Correa ha demostrado un manejo de la oratoria capaz de captar la atención hacia sus discursos, incluso de sus opositores. Cuenta, además, con un carisma que le ha facilitado la cercanía de los sectores más vulnerables y humildes del país y que le ha valido el reconocimiento de otros presidentes del mundo.

Antes de su primera elección en 2006, el país atravesaba por una de las peores crisis económicas y políticas de su historia. Así, Correa encontró el entorno ideal para presentarse como el candidato fresco, sin pasado político de mayor relevancia, sin asociaciones con los partidos políticos tradicionales y con un discurso y modo de actuar populista, que le permitía acercarse a un electorado masivo.

Son varios los trabajos publicados que abordan aproximaciones a las candidaturas y gobiernos de Rafael Correa. Es el caso, por ejemplo, del de José Rivera Costales (2006), en el que se analiza el cambio en la propaganda política ecuatoriana a partir de la primera candidatura de Correa. Asimismo, se revisó el trabajo de Esperanza Morales López (2012), un análisis del discurso de Rafael Correa, en el que la autora analiza "desde un punto de vista pragmático-discursivo y retóricoargumentativo las características ideológicas (o construcciones discursivas) de las alocuciones del presidente Correa." (Morales López, 2012)

De igual manera, el trabajo publicado por Rúas-Araujo et al (2017) analiza los discursos institucionales de Correa desde 2007 hasta 2015, con el fin de distinguir diferencias, tanto de forma como de fondo, en cada uno de sus gobiernos. Quizás uno de los estudios más cercanos al nuestro sea un trabajo cuyo objeto de análisis es el spot "La bicicleta"; se trata de un artículo en el que María Laura Ferrandi y Antonela Fric analizan el mensaje político que el vídeo trata de posicionar.

Rafael Correa llegó, entonces, como el salvador del país, como un mesías laico que venía a construir la patria soñada y a enfrentarse a todos aquellos políticos, burócratas y partidos que, según él, tanto daño habían hecho al país. Así, empezó a construir su discurso sobre la renovación de una patria en la que todos los ecuatorianos se sintieran incluidos. De esta manera, la "patria" pasó a ser uno de los conceptos recurrentes en sus discursos, mensajes a la nación y, por supuesto, en su propaganda electoral y gubernamental. Ese mismo concepto "patria" será, por este motivo, el centro sobre el que girará nuestra investigación. Esta construcción de patria será, sin embargo, analizada a partir de su utilización política, especialmente en los gobiernos de las construcciones bolivarianas, como lo explica Felipe Burbano de Lara (2015) en su artículo "Todo por la patria. Refundación y retorno del estado en las revoluciones bolivarianas".

La recurrente alusión a la patria en los discursos presidenciales nos llevó a preguntarnos sobre el papel que cumplía este concepto en la narrativa de los gobiernos de Correa. De ahí que, al inicio de nuestra investigación, nos planteamos la 
hipótesis de que el uso que Rafael Correa da al término "patria" en sus spots electorales tiene, fundamentalmente, fines propagandísticos, encaminados a la construcción de una nueva identidad nacional, coherente con el proyecto político que lo llevó a la presidencia.

A partir de la selección de los citados spots, así como del planteamiento de la hipótesis, hemos podido trazar, como objetivo de la investigación, analizar y describir el uso del concepto "patria" en la comunicación política de Rafael Correa, especialmente en los spots electorales. Además, simultáneamente, profundizaremos sobre la relación entre comunicación y poder en el contexto ecuatoriano para establecer una aproximación al génesis del uso propagandístico del término "patria" en el contexto ecuatoriano y latinoamericano. De esta manera, nos proponemos determinar en qué medida la utilización del concepto "patria” que presenta Rafael Correa en sus spots electorales tiene fines propagandísticos y pretende construir un sentimiento identitario.

\section{Populismo del siglo XXI}

La persuasión y la manipulación de los líderes a sus pueblos han estado presentes en la humanidad prácticamente durante toda su historia. Evidentemente, hablar de propaganda desde la antigüedad, tal como comprendemos el concepto actualmente, sería inadecuado, ya que el término se ha tornado cada vez más complejo y masivo. Así, es ahora objeto de estudio político y académico, lo que ha derivado en gran variedad de aproximaciones teóricas.

Alejandro Pizarroso Quintero (1990) explica que la propaganda "con- siste en un proceso de diseminación de ideas a través de múltiples canales con la finalidad de promover en el grupo al que se dirige los objetivos del emisor no necesariamente favorables al receptor; implica, pues un proceso de información y un proceso de persuasión” (1990, p. 28). Además, plantea que la propaganda suele partir de una organización que funcione, al mismo tiempo, como difusora de información, controladora de la misma y ente persuasor.

$\mathrm{Al}$ respecto, argumenta que "la propaganda es un proceso de persuasión porque, en efecto, implica la creación, reforzamiento o modificación de la respuesta; pero también es un proceso de información, sobre todo en lo que se refiere al control del flujo de la misma" (1993, p. 27). Una de las organizaciones creadoras de propaganda más habituales son los gobiernos, debido a su necesidad de proponer y establecer ideología, así como de construir imaginarios sociales acordes con sus necesidades de permanencia en el poder. Por lo tanto, argumenta que aquí hallamos "la posibilidad de discernir y diferenciar al fenómeno propagandístico de otros fenómenos comunicativos." (ídem)

Adrián Huici (1996), por su parte, afirma que la característica inherente de la propaganda política es que "debe situarse en la esfera de lo ideológico, puesto que de lo que se trata es de consolidar, implantar o modificar opiniones" (p. 35). Así, la propaganda política trata de difundir algún "objeto de carácter ideal o conceptual cuya máxima difusión interesa para la consolidación y mantenimiento del emisor que, en líneas generales, suele ser el mismo estado." (p.36)

Este fenómeno se observa en todos los estados, en mayor o menor medida, a 
través de medios y con objetivos variados, que pueden estar orientados a fomentar el sentimiento nacionalista o a "reforzar el prestigio de un estado y sus símbolos bajo todas sus formas: bandera, himno nacional, condecoraciones, líderes (...)" (Driencourt, 1964, p. 326). Asimismo, la propaganda cumple hoy un papel de constructor de identidad con la finalidad de lograr la cohesión interna, proyectada en imaginarios sociales colectivos. De hecho, resulta difícil pensar en otra forma de construcción identitaria que no sea a través de la comunicación en general, y de la comunicación política en particular.

Así, podemos entender la propaganda política de la actualidad como un instrumento de los diferentes regímenes políticos para consolidarse. "La propaganda se convierte para él (el Estado) en una necesidad absoluta, que condiciona su supervivencia" (Driencourt, 1964, p. 328). Entonces, la propaganda política no sólo participa de la democracia, sino que es imprescindible para su mantenimiento.

Jacques Driencourt (1964), afirma que "la propaganda es una técnica para obtener adhesión" (p. 44) y además cree que "puede ser intencionada o inconsciente" (p. 49). De esta manera, el autor se separa de las teorías de otros, como Pineda, que creen que en política, al hacer propaganda, nada es fortuito, sino que cada acción responde a intereses. Sin embargo, el autor es consciente de la necesidad de las organizaciones hegemónicas de perpetuar y consolidar su poder, por lo que afirma que, para cualquier sociedad, frente a la propaganda, "es inútil sublevarse y sería infantil negar su existencia." (Driencourt, 1964, p. 51)

Como parte de la democracia, la propaganda resulta especialmente visible en los periodos electorales. En este caso, la intención es persuadir a los receptores para que actúen de acuerdo con los intereses del emisor, es decir, que los voten favorablemente. Como afirma Ana Belén Campillo (2013), la propaganda electoral cumple funciones de "información y adoctrinamiento", ya que expone sus principios ideológicos y sus propuestas de trabajo, al mismo tiempo que manipula para convencer al electorado.

La propaganda electoral, además, juega siempre a contrarreloj. Normalmente, las campañas para períodos de elecciones son limitadas, por lo que la rapidez para convencer y manipular juegan un papel fundamental. Así, observamos que ésta debe ser lo suficientemente sólida como para posicionarse en un tiempo corto, pero también debe tener la capacidad de adaptarse a la coyuntura; es decir, conforme se obtengan resultados de sondeos, fortalecer el mensaje o cambiarlo, según las necesidades. (Campillo, 2013)

Asimismo, la propaganda electoral, habitualmente, se construye alrededor de la contra propaganda. Mario Herreros (1989) explica que los candidatos, aparte de reforzar sus propuestas y su imagen, deben oponerse a las de sus adversarios y ser críticos frente a ellos. Esto, además de dar mayor relevancia a su discurso, construye una imagen de líder clásico, dispuesto a luchar. No obstante, esto no implica necesariamente utilizar una técnica de confrontación, sino hacer sobresalir las ideas propias sobre las ajenas (Capdevila Gómez, 2014). En época electoral, es indispensable que el líder que va a ser protagonista en la propaganda cuente con simpatía que le faciliten la convicción y la manipulación. Esto, además de fortalecer su imagen de liderazgo, 
le permite colocar imaginarios de manera más amigable $\mathrm{y}$, por lo tanto, a través de la empatía, lograr persuadir. (ídem)

Muchos de los cambios que han afectado a la propaganda, han tenido que ver con el desarrollo de la tecnología. Así, en la actualidad, la propaganda audiovisual ha ganado terreno, no sólo por la posibilidad de presentar imágenes que acompañen a los discursos, sino que además se han convertido en un recurso fundamental para llegar a una mayor cantidad de público. Es así que los Estados han sabido utilizar esta "nueva" herramienta para construir identidad y difundir, a menudo, la idea patriótica. Mención aparte merecen, en nuestro estudio, los spots electorales, realizados para conseguir, habitualmente en poco tiempo, el máximo apoyo posible a un candidato, una propuesta o un partido.

\section{Uso propagandístico de la historia}

El concepto de "patria" que nos ocupa en este trabajo suele llevar consigo un relato histórico construido ad hoc, con el objeto de consolidar la idea de que el grupo en cuestión posee un pasado común que le da sentido. Por esto, es habitual que la construcción de las patrias incluya un cierto uso propagandístico del pasado nacional.

El uso político de la historia por parte de las élites en el poder poco tiene que ver con el trabajo "científico" de los historiadores; así, serán estas élites quienes busquen acontecimientos y personajes que se ajusten a sus necesidades actuales. Caso contrario, simplemente se hará una adaptación -por conveniencia- de lo que se conoce, es decir, que el uso político de la historia "implica la jerarquización de la realidad y "censura" de lo no seleccionado.” (Vázquez-Liñán \& Leetoy, 2016)

El uso de la historia y sus símbolos con fines propagandísticos no es reciente; desde la existencia de los estados-nación se ha recurrido a la historia para construir identidad nacional y afianzar en esta un discurso patriótico. Explica Tzvetan Todorov que esta "técnica" estuvo, durante el siglo XX, directamente asociada a los regímenes totalitarios, como vemos en el caso del Reich en Alemania o de la Unión de Repúblicas Socialistas Soviéticas (URSS), en donde los gobiernos se habían encargado de "sistematizar su apropiación de la memoria y han aspirado a controlarla hasta sus rincones más recónditos." (Todorov, 2000, p. 14)

No obstante, en la actualidad es difícil encontrar representantes políticos que no hagan un uso político de la historia, algo que se hace especialmente explícito en los periodos de campaña electoral. Este uso político del pasado puede tener objetivos diversos, que van desde la unificación de ciertas "tradiciones inventadas", hasta la construcción de proyectos políticos, éticos para el futuro. La memoria es también justicia para el presente y esperanza de futuro.

El poder del discurso es esencial para la práctica política: "Si el discurso controla las mentes y las mentes controlan la acción, para quienes ocupan el poder controlar el discurso es absolutamente esencial" (Van Dijk, 2009, p. 31). En la actualidad, tal como ya se ha mencionado, la propaganda es fundamental para cualquier estado, la construcción de un buen discurso efectivo será una herramienta crucial en la consolidación de un determinado proyecto político, habitualmente ideológico, con pretensiones de mantener o modificar cierto imaginario. 
Para mantener el orden y asegurar la estabilidad del poder y el mantenimiento de la hegemonía, es habitual en los Estados el esfuerzo por generar un sentimiento identitario en la población. Para lograrlo, como ya se ha mencionado, el uso de símbolos es fundamental, ya que traducen en algo más tangible aquel sentimiento de pertenencia nacional al que apelan los gobernantes, y la idea de "patria” se hace material en sus símbolos, rituales, costumbres o tradiciones.

La creación de una patria consiste en "puras relaciones de interioridad" (Laclau \& Mouffe, 1987, p. 31), es decir en conseguir que la idea de nación, entendida como territorio y sus componentes, sean asumidas como propias por los habitantes de la misma. Para esto, nuevamente, es necesario recurrir a la historia y hacer uso de ella como fuente de heroísmo y patriotismo. Hablar de "patria" y de "propaganda" en un mismo contexto y con una intención clara de vincular ambos conceptos, nos lleva de nuevo a la historia. Por esto, es apropiado partir de una definición que abarque todo aquello a lo que hace referencia la propaganda al abordar el concepto de "patria".

La patria es esa nación-estado que, como comunidad, nos incorpora como sus integrantes. Es también el conglomerado de sus habitantes, que son conscientes de su pertenencia no solo por motivos de relación de familias y parentescos, sino por tener una ciudadanía en común. La patria es, en fin, el patrimonio material y cultural, como las tradiciones, la lengua, la historia colectiva, los recursos naturales. (Ayala Mora, 2002, p. 78)

La patria, al ser un símbolo intangible, es fácil de ser manipulada, por lo que se ha convertido en un recurso propagandístico en política. Cada Estado utiliza el término a su conveniencia, es decir "amolda" la patria a sus necesidades. El concepto de "patria", aunque se remonte a tiempos de fundaciones e independencias de los estados, ha ganado protagonismo en los últimos años, sobre todo en Latinoamérica, en donde la corriente de gobiernos autodenominados "Socialistas del siglo XXI", ha recurrido constantemente a éste.

\section{Ecuador: una nación con memoria a corto plazo}

Podría parecer que en el siglo XXI, marcado por tendencias globalizadoras, hablar de identidades nacionales y patriotismo resulta un tanto obsoleto. Sin embargo, no parece que sea del todo así. Sentirse identificado con algo considerado como propio es no sólo inherente al ser humano, sino que, además, parece cada vez más necesario para enfrentar al mundo de la tecnología y la velocidad en el que estamos: "En un mundo globalizado como el nuestro, la gente se aferra a su identidad como fuente de sentido de sus vidas" (Castells, 2003). Explica Castells, en su análisis de la identidad nacional que, aunque puede que el término esté "mal visto", los sentimientos identitarios y/o patrióticos están, en la sociedad reel que él mismo ha definido, más presentes que nunca. Así, el autor afirma que buena parte de los conflictos que se desarrollan actualmente, "se remiten casi siempre a la defensa de identidades agredidas" (ídem). De esta manera, el primer paso para consolidar una identidad es asumirla y hay que hacerlo teniendo una visión de que ésta, la propia, es distinta a cualquier otra con la que se compare.

En el caso concreto de Ecuador, la complejidad de la identidad nacional y el pa- 
triotismo no ha sido menor. Aunque el país no ha sido víctima de gobiernos puramente dictatoriales o fascistas que hicieran uso permanente del patriotismo, como mensaje propagandístico para los ecuatorianos siempre ha resultado difícil sentirse identificados con la nación. Es así que, por muchos años, se ha hablado de una crisis de identidad nacional que impedía a la ciudadanía unirse en torno a un sentimiento común.

Ecuador no ha sido una excepción en diseminar a través de sus instituciones (el sistema escolar, los partidos políticos, la burocracia, los medios de información, etc.) ese imaginario de nación, en donde las diferencias basadas en la "raza", el color de la piel, la clase social, el género o la región son pasadas por alto, para producir consenso y legitimar la gestión de las clases dirigentes alrededor de una simbólica unidad nacional. Sin embargo, los discursos nacionalistas han tenido en el contexto ecuatoriano mucho de retórica patriotera y muy poco de expresiones prácticas. (Traverso, 1998, p.291)

Miguel Donoso Pareja, pensador ecuatoriano, explica que para los ciudadanos de Ecuador es difícil "identificar los rasgos específicos de su identidad, pero todos saben que está ahí" (Donoso Pareja, 2004, p. 33). Sin embargo, afirma el autor que la solución se encuentra en que "nos sentimos identificados en todo aquello que nos valoriza y nos enorgullece, aunque sea transitorio" (Ídem). Es allí, en lo transitorio, en donde precisamente radica lo interesante de la identidad ecuatoriana y el nacimiento y crecimiento del sentimiento patriótico. Son acciones puntuales o personajes con alguna trascendencia en un determinado momento quienes se han vuelto embajadores de paso de nuestra identidad, $\mathrm{y}$ han sido fundamentales para la construcción de la misma.

Así, observamos que la dificultad de consolidar el patriotismo radica, en buena medida, en la diversidad de grupos sociales que coexisten en territorio ecuatoriano $^{1}$. Entonces, cada uno de estos grupos tendrá diferentes símbolos con los cuales identificarse colectiva e individualmente: "El significado funcional de las actitudes sociales individuales, sentido de pertenencia y aspiraciones dependen pues, en gran medida, del contexto grupal del cual emanan" (ídem, p. 297). Por este motivo, ha sido necesario recurrir a eventos y/o personajes puntuales que logren empatía en todos los grupos sociales.

Tanto Enrique Ayala Mora (2002) como Miguel Donoso Pareja (2004) atribuyen el primer lugar en la consolidación del patriotismo al deporte. Ver a Jefferson Pérez ganar en Atlanta 1996 la primera medalla olímpica de oro para Ecuador o ver a la selección de fútbol clasificarse a su primer mundial en 2002 o avanzar hasta la segunda etapa del torneo en 2006, son acontecimientos que han enaltecido el orgullo nacional y que forman ya parte emocional de la identidad ecuatoriana. Como en otros lugares del mundo, en el Ecuador actual, el deporte se ha usado políticamente para promocionar una especie de patriotismo pretendidamente "apolítico".

La "vulnerabilidad nacional" ecuatoriana no ha sido del todo negativa. Aunque los rasgos de identificación sean transito-

1 En el censo poblacional de 2010, se agrupó a la población en cinco macro grupos: mestizos, blancos, montubios, afroecuatorianos e indígenas. Si bien, la mayoría de los ecuatorianos se consideran mestizos (71\%), el resto afirman pertenecer a los otros grupos identitarios, que están compuestos por decenas de subgrupos. Si se desea revisar las cifras completas, véase: http://www.ecuadorencifras.gob.ec/poblacion-y-migracion/ . 
rios, esto ha dado paso a que el ecuatoriano se emocione y conmueva con acontecimientos que en otras sociedades pudiesen pasar inadvertidos. Así, por ejemplo, si una película ecuatoriana resulta precandidata a un Oscar, el país se vuelca a brindarle su apoyo; o si un cantante tiene la posibilidad de ganar un Grammy, tendrá a todo el país siguiendo sus pasos. Entonces, "aunque la mayoría de sujetos se identifiquen como ecuatorianos, esa filiación resulta significativa sólo en momentos muy puntuales." (Traverso, 1998, p.294)

\section{Metodología}

Para el presente estudio, se han seleccionado dos spots que corresponden a los períodos electorales de 2009 y 2013 , es decir las últimas dos candidaturas de Rafael Correa a la presidencia. En ambos casos, los vídeos presentados corresponden a productos oficiales de la candidatura. No obstante, en el caso del spot de 2013, por su duración ( $\left.3^{\prime} 31^{\prime \prime}\right)$, fue presentado en su versión completa únicamente en redes sociales, pero en televisión fue adaptado a varios vídeos más cortos.

Si bien el objetivo de esta investigación es la comprensión del uso del término "patria" en los spots electorales de Rafael Correa, los vídeos serán interpretados en su totalidad, aunque con especial énfasis en nuestro objeto. Además, tomaremos en cuenta el entorno en el que se desarrolló cada uno, considerando los datos presentados en el marco histórico. Esto lo haremos de acuerdo con el enfoque cualitativo elegido, ya que nos indica que "su perspectiva es fenomenológica. (...) Se debe tomar en cuenta lo que la gente dice o hace en su propio mundo, cómo percibe su entorno, su marco de referencia, problemas, necesidades o ilusiones." (Soler, 2011, p. 191)

Enmarcados en esta metodología, trabajaremos el análisis del discurso. Éste plantea una interpretación del "qué se dice y cómo se dice (...), tanto el contenido manifiesto del texto, como el contenido latente del mensaje, su significado, de manera que se encuentren claves para su interpretación.” (Velázquez, 2011, p. 237) Es por esto que, para poder utilizar este método, primero se ha presentado un contexto general de la situación en Ecuador, sobre la que se sostienen estos productos comunicacionales.

Si bien el enfoque y el método escogidos no son los únicos que podrían permitirnos cumplir los objetivos de nuestra investigación, su elección se justifica por la posibilidad que nos ofrecen de interpretar una realidad dentro de su contexto, así como los posibles impactos que hayan tenido en la sociedad en la que se desarrollaron.

\section{Análisis}

\section{Spot 1}

Este spot inicia con música instrumental y nostálgica, que recuerda a un pasillo². Esta elección no es casual, sino el

2 El pasillo es el género de música tradicional ecuatoriano, que se caracteriza por su sentimiento melancólico y el uso de la guitarra clásica Es un "texto poético-musical arraigado a una gestión personal de sentimientos de los ecuatorianos, es una manifestación cultural" (Granda, 2004). Sus orígenes se relacionan con el vals austríaco, que se escuchó por primera vez en América con la llegada de los españoles. A partir de entonces, los criollos (hijos de españoles) adoptaron el género musical, lo adaptaron y popularizaron. Históricamente, los mayores representantes internacionales de Ecuador, musicalmente, han sido cantantes de pasillo, como es el caso de Julio Jaramillo, cuya fama alcanzó a toda la región. Hasta hoy, el pasillo constituye la música nacional por excelencia, con canciones emblemáticas que han sido cantadas en innumerables versiones. Para consultar más sobre este género, véase: Granda, 2004. 
primer elemento de una cuestión estética que forma parte del concepto de construcción patriótica. Desde este primer momento, entonces, el espectador se adentra en el sentimentalismo, herramienta recurrente de la propaganda política actual, con el afán de lograr mayor empatía con el pueblo, así como de los líderes populistas que acuden con frecuencia a la emotividad, tal como ya hemos comentado en el marco teórico.

\section{Fotograma 1}

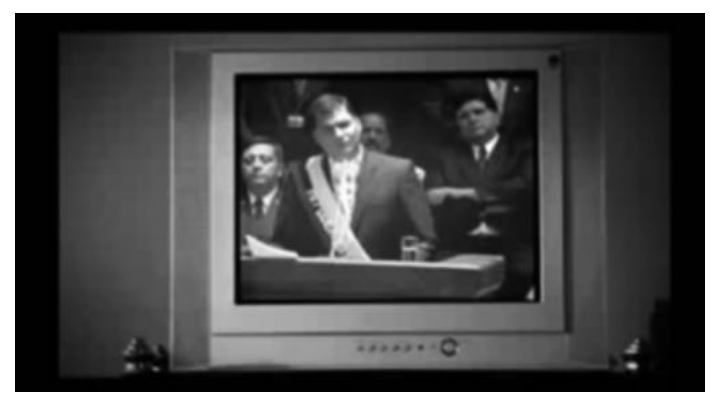

Más adelante, se escucha la voz de Rafael Correa en un tono moderado, pacífico y conciliador y, paralelamente, aparece su imagen a través de un televisor que, conforme la cámara se aleja, vemos que pertenece a un hogar de condición humilde. (Fotograma 1) Este recurso, al igual que la música, busca remitir la sensación de cercanía del mandatario con el ciudadano común, a tal punto de que se adentra y forma parte de sus hogares.

$\mathrm{Al}$ iniciar el discurso, Correa hace referencia a su "[mi] patria morena" (PAIS, 2009) y la califica de humilde y sencilla. Al utilizar estos términos, el presidente se está apropiando de la patria, no solamente por utilizar el adjetivo posesivo, sino porque además habla de tener sueños y construir realidades alrededor de ella. Al analizar el contexto que pre- senta el anuncio, se nota que "patria morena" hace referencia justamente a los sectores vulnerables de la sociedad que aquí se presentan. Históricamente, los grupos minoritarios como indígenas, afroecuatorianos o gente extremadamente pobre, se han visto marginados, pero, en este caso, es a ellos a quien el presidente está dirigiendo su discurso.

El mandatario, además, habla de la transformación de la patria como un acto heroico. En su discurso, se refiere al pasado con aspectos negativos y habla de soluciones para el presente. Este pasado al que Correa hace referencia es el que mencionamos en el contexto histórico: un pasado que fue una época convulsa de la crisis económica que obligó a millones de ecuatorianos a abandonar el país y que trajo consigo un feriado bancario que afectó a miles de familias. Este pasado, tal y como hemos apuntado, fue causado por gobiernos tildados de neoliberales y oligarcas, por lo que esta referencia a aquella época sirve para desvalorizar cualquier proyecto opositor, tuviera o no relación con la crisis. Así, por ejemplo, Correa afirma que sueña "con una patria sin niños en la calle y sin opulencia, pero digna y feliz" (PAIS, 2009).

Posteriormente, continúa refiriéndose a la patria que desea y que, por lo tanto, aunque no lo mencione explícitamente, va a construir su gobierno. Correa habla de "una patria amiga para todos" (PAIS, 2009) afirmación que no sólo refleja la necesidad de inclusión en la construcción de imaginarios, sino que va acorde con su tradicional eslogan de "La patria ya es de todos". Mediante estos recursos, se marca una cuestión crucial de la política y el populismo actuales: la dinámica aliado-adversario, es decir, como habíamos mencionado en los capítulos 
anteriores, buscar enemigos comunes y ser líder en la lucha contra ellos. Entonces, el discurso tendría una dinámica de la patria es ahora -conmigo- amiga de todos, mientras que antes fue de los políticos que la sumergieron en la crisis.

Jamás, jamás defraudaré a mis compatriotas y consagraré todo mi esfuerzo con la ayuda de Dios, bajo la sombra libertaria de Bolívar y Alfaro a luchar por mi país, por esa patria justa, altiva y soberana, que todos soñamos y que todos merecemos. (PAIS, 2009)

\section{Spot 2}

En 2013, Rafael Correa se postula nuevamente a las elecciones presidenciales de Ecuador. Esta fue su tercera y última vez como candidato y su tercera victoria consecutiva. Con una trayectoria política más consolidada y las estadísticas de aceptación a su favor -en 2013, rondaban el 62\%-, la campaña iba a resultar relativamente sencilla, tan solo haciendo un uso inteligente de estas condiciones. Es así que su equipo de comunicación puso en marcha un único spot de campaña en estos comicios. Este anuncio tiene una duración de tres minutos y medio, por lo que, para transmitirlo en televisión, se utilizaron varias versiones reducidas del vídeo, mientras que en redes sociales, estuvo disponible la versión completa.

En este anuncio, Correa es el protagonista absoluto: su voz en off y su imagen son el eje conductor en todo momento. El inicio del vídeo es clave y nos marca una pauta de cómo se desarrollará, ya que vemos al presidente con vestimenta formal y desprendiéndose de su banda presidencial, es decir metafóricamente renunciando al poder por un momento, para estar al mismo nivel que sus ciudadanos (Fotograma 5). Este gesto busca nuevamente la cercanía del mandatario y su capacidad de colocarse en el lugar de su pueblo. Continuando con este proceso, Correa se viste con su ropa deportiva, se coloca una chaqueta que tiene la bandera de Ecuador en el pecho, toma su casco, su bicicleta y se prepara para salir.

\section{Fotograma 5}

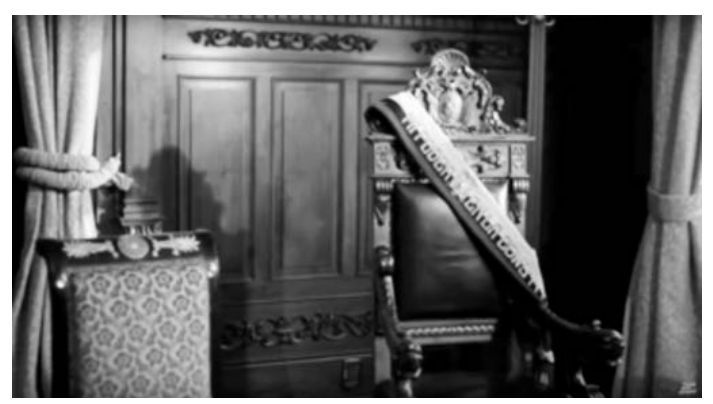

Desde el inicio del spot, escuchamos música instrumental. Al igual que en el caso anterior, ésta tampoco ha sido elegida al azar y corresponde a la ya característica canción utilizada por Alianza PAIS, "Patria, tierra sagrada" que, como se ha mencionado, está cargada de mensajes de patriotismo y ha sido acogida por este partido político casi como un himno de su proyecto político.

En cuanto al discurso de este spot, lo primero que llama la atención es la tonalidad con la que Rafael Correa se expresa. Al igual que en la pieza audiovisual anterior, su voz evoca nostalgia, sentimentalismo y una pasividad de la que no hace gala en otras intervenciones políticas. El contenido del discurso, como se ha manifestado, ocurre con frecuencia en propaganda política, recurre a los imaginarios sociales que son compartidos por la sociedad. El primero de estos imaginarios colectivos que se menciona es direc- 
tamente en la primera oración pronunciada: "Desesperanza, ese era el nombre de la patria" (PAIS, 2013). Este es el ejemplo más claro de que las ideas de renovación de PAIS están construidas sobre un cimiento de desaliento que se había tomado a los ecuatorianos. La comunicación del candidato encuentra, además, en este anuncio, una oportunidad de repetir frases recurrentes del mandatario. "Con manos limpias, mentes lúcidas y corazones ardientes por la patria”. Así, Correa intenta destruir el imaginario que asocia a todos los políticos con corrupción y frivolidad, pretendiendo construir alrededor de sí mismo y su gobierno una idea de político distinta a la usual.

Luego de todas estas contraposiciones, vuelve a recurrir a la patria para adjetivarla; sin embargo, ya no negativamente como al inicio del video, sino con los nuevos atributos que él - o nosotros - le ha dado. Así, Correa habla de que "hoy, la patria está llena de dignidad, de respeto, de autoestima, de amor por la vida" (PAIS, 2013). Esta construcción de patria es a la que el presidente se refiere cuando habla de sus sueños y es esta la que quiere que se posicione como imaginario en el colectivo. Además, como se ha explicado, una de las críticas recurrentes a Rafael Correa es haber creado su imagen como la de único líder posible de la Revolución Ciudadana. Como respuesta, en su discurso, se presenta como un líder más inclusivo y dice que lo logrado "no es la victoria de un hombre, ni de un partido, es la victoria definitiva de todo un pueblo." (PAIS, 2013)

El spot concluye con una imagen y una oración que resumen todo lo explicado. Rafael Correa deja su banda presidencial en la casa de unos indígenas que lo acogieron, nuevamente haciendo alu- sión a que el poder no es de él, sino del pueblo. Luego, sube a una colina y, dirigiéndose a la cámara, exclama: "La patria volvió para siempre" (PAIS, 2013). Evidentemente, desde su concepto más literal, la patria siempre estuvo ahí, pero en este caso, por su utilización propagandística, Correa se refiere a su -o nuestrapatria, la que dejo atrás el pasado desesperanzado y ha empezado un nuevo camino mucho más positivo. Hablar de "para siempre", además, hace referencia a que, aunque pueda darse nuevamente un giro en la tendencia política de la región y/o del país, las "conquistas" del "Socialismo del siglo XXI" no podrán olvidarse ni revertirse, lo que garantiza que su proyecto político siga vivo.

\section{Campaña audiovisual}

El discurso de ambos productos audiovisuales se basa en promover una ideología y fortalecer políticas, a través de la imagen de un candidato que se ve reforzada por los sistemas de comunicación y poder que responden hegemónicamente al Estado. Si comenzamos a analizar el discurso, lo primero que llama la atención es que Rafael Correa, a pesar de que en ambas ocasiones ya tenía una imagen bien posicionada como líder, se coloca en el lugar del ciudadano común, tanto con sus palabras, así como en la entonación y los gestos que las acompañan. Contrariamente al tono de voz habitual de Correa, en estas dos ocasiones lo vemos pacífico, moderado e inclusivo, con cierto tinte nostálgico al hablar del Ecuador que anhela.

A partir del discurso, además, podemos ver que otra de las intenciones claras es la de resaltar la condición de servicio 
de Rafael Correa, tal como apuntan las características de los líderes populistas; sin embargo, si analizamos con mayor profundidad, observamos que el eje principal de ese servicio radica en la patria. Es decir, su trabajo se fundamenta, según sus palabras, no directamente en las personas, sino en que ellas vivan en una mejor patria y, sobre todo, tengan una mejor concepción de ésta. Esta condición está relacionada con el "buen vivir", en el que tanto énfasis pone la "Revolución Ciudadana”.

El discurso en ambos vídeos está además construido sobre imaginarios sólidamente arraigados en la sociedad ecuatoriana. Entre estos, sobre todo, se destaca la relación de la pobreza, la desesperanza o la corrupción con la situación del país antes de su llegada y que es utilizada como contraste para resaltar lo positivo de su gobierno. Así, como habíamos apuntado en el marco teórico, en propaganda, la estrategia no consiste únicamente en recurrir a imaginarios colectivos, sino además en reconstruirlos o construir nuevos que ayuden a la consolidación de una ideología. Tal es el caso, que Rafael Correa basa gran parte de sus discursos en lo que él llama "la nueva patria”.

La técnica discursiva en él y su equipo de comunicación implementan se construye, entonces, sobre dos ejes fundamentales: quebrar el pasado y construir un mejor futuro. Para esto, el recurso al que han acudido es hablar del renacimiento de la patria, como estrategia de persuasión en la que Correa consolida su imagen como héroe y, tal como se explicaba en el personalismo, presentarse como "mesías laico o salvador de una sociedad predispuesta a la salvación." (Floria, 1961, p. 67)
Entonces, se puede afirmar que el imaginario colectivo en el que Correa basa ambas campañas es la noción de una nueva patria por la que trabajan él y su equipo. Este imaginario de la patria nueva se construye a través de distintos componentes, como las referencias a los próceres cuyo pasado se ha politizado según la conveniencia de los intereses de la "Revolución Ciudadana" o al hablar de victorias definitivas en las que "la patria vuelva a estar en manos de todos". Como ya mencionaba Laclau, el concepto de la patria se construye hegemónicamente y en muchas ocasiones fundado sobre las bases del populismo. Afirmaba el estudioso, junto a Mouffe (1987), que la patria se construye sobre "puras relaciones de interioridad", es decir, sobre imaginarios que están sumamente arraigados en el colectivo y que pueden actuar como motor para tomar una decisión en una elección presidencial.

Un factor importante a tomar en cuenta es el poder que se le otorga a la palabra de Rafael Correa en ambas campañas. En ninguno de los dos spots vemos al mandatario aparecer con alguien de su equipo, ni siquiera nombrarlos o explicar algún plan político para su, aún posible, futura presidencia. Así, observamos que la hegemonía no se ejerce sólo desde la política a los ciudadanos comunes, sino que, además, dentro del propio partido de Correa se observa un liderato indiscutible, asumido ya no solamente por él, sino, como se evidencia en los vídeos, por todo el equipo que maneja la comunicación detrás de él. Además, nuevamente observamos que el personalismo de Correa está claro, incluso dentro del propio partido. Está claro, entonces, también, que lo que se está vendiendo no es un programa, es una idea de país, de patria. 
$\mathrm{Al}$ analizar ambas piezas en conjunto, observamos que existe una concordancia en los discursos, por lo que, aunque sepamos a qué elección pertenece cada uno, tranquilamente se podría optar por utilizar cualquiera de ellos en cualquiera de sus candidaturas y, es más, en su propaganda presidencial. Este factor demuestra que el discurso de Correa a lo largo de todos sus años en la presidencia, ha sido continuo, manteniendo como eje principal su sueño de patria. Por este motivo, Rafael Correa no sólo ha recurrido a la repetición de ideas, sino que, para hacerlo más evidente, reitera frases construidas constantemente. "La patria soñada”, "con mentes lúcidas", "tenemos los corazones ardientes", "la patria desesperanzada”, son tan solo algunos ejemplos de las frases que funcionan como una especia de muletilla en los discursos de Correa. Como podemos notar, todas hacen referencia al quiebre del pasado y, por supuesto, al eje de su comunicación.

En el inicio de los spots se notan tintes sentimentalistas, por las condiciones en las que está la patria, pero conforme avanzan las palabras del presidente, se van presentando imágenes más esperanzadoras, es decir paisajes como el mar, las carreteras amplias y modernas o casas llenas de gente feliz y esperanzada. Estos demuestran el trabajo, tanto el ya hecho por Correa y su equipo, como aquel al que se están comprometiendo a seguir haciendo para recuperar la patria y hacerla libre de aquellos antiguos políticos quienes, según Correa, habían acabado con ella, es decir, los enemigos comunes de los que nos habla la teoría del populismo.

El discurso de Correa, enfocado en el renacimiento de la patria, puede ser analizado a partir de una paradoja. Por un lado, la presentación democrática de un gobierno que renueva la esperanza y, por el otro, la utilización propagandística de una necesidad tan indispensable en aquel momento de la historia política ecuatoriana como la de recuperar una patria que para muchos estaba perdida en manos de la burocracia neoliberal, como la ha denominado el mismo Rafael Correa. Entonces, podemos decir que la dualidad radica en los elementos de persuasión utilizados en estos vídeos que, como se ha mencionado, podrían ser criticados por banalizar las necesidades populares o simplemente podrían ser vistos como un recurso de las herramientas de propaganda más esenciales, cuyos ejes son los imaginarios colectivos.

Los dos spots de propaganda electoral de Correa pretenden construir alrededor de las necesidades de la patria a un "superhombre". Tal como se desprende de su discurso, su lenguaje corporal y sus acciones explícitas, Rafael Correa se presenta como un héroe, con retos enormes y enemigos importantes y poderosos, pero que, ante él, solamente representan obstáculos para alcanzar la patria soñada.

Si bien estamos analizando únicamente dos discursos de Rafael Correa y que además son preelaborados y corregidos para aparecer en un vídeo, éstos representan una muestra clara de su política, así como de su proyecto de gobierno. Como ya se ha establecido, el eje de su política es la patria y será alrededor de ésta que se construirán los eslóganes, las frases construidas y reiteradas constantemente por Alianza PAIS y, sobre todo, los imaginarios colectivos que deban sustituirse o, en otros casos, crearse. 


\section{Conclusiones}

En un país como Ecuador, en el que los problemas identitarios han sido una constante, Correa ha sabido aprovechar su oportunidad coyuntural y, a través de la masiva difusión de la idea de una "patria para todos", conseguir cierto refuerzo de identificación. El discurso de Rafael Correa ofrece una patria igualitaria para los ecuatorianos que él considera vulnerables y a los cuales puede presentarse como un héroe salvador. Su discurso, asimismo, logra involucrar al pueblo en su proyecto político, así como la empatía sobre todo con los sectores más populares, al ubicarse a su mismo nivel. Al ofrecer una patria inclusiva, Correa está además trabajando en el tema identitario. Al construir un discurso de cercanía al pueblo e incluir constantemente referencias a la necesidad de defender y luchar por la patria, ha conseguido que los ecuatorianos sientan la necesidad de hacer lo mismo, es decir, de proteger la patria de los enemigos que ha establecido Correa, por sentirla como propia.

El concepto de "patria" al que se refiere Rafael Correa en sus spots electorales está construido sobre un significado propio que él ha dado al término. Es así que observamos que Correa y su equipo de comunicación han construido esta resignificación de la idea de "patria" con dos fines: por una parte, recordar las características negativas que se habían atribuido al término, con el fin de desprestigiar al pasado y, por otra, asociar este nuevo significado a una renovación y rescate de la misma, que asocie su imagen con un cambio positivo.

Es aquí en donde queda en evidencia un rasgo típico del líder populista: presentarse como un mesías laico, dispuesto a luchar por la patria, enfrentándose a enemigos que él mismo ha definido. Así, es evidente que el discurso cae permanentemente en adjetivaciones negativas sobre la historia "pre-Correa", así como de la idea de patria que, hasta su llegada al poder, había sido hegemónica en Ecuador. Desesperanza, miedo, pobreza y corrupción, son sólo algunos de los tópicos principales con los que su propaganda asocia al pasado. En oposición a esta retrospectiva, en el presente y el futuro ha de construirse la "patria soñada". Esta patria soñada es la que él construye desde su gobierno, pero que enfatiza en conseguirla a través del trabajo conjunto con el pueblo. De esta manera, observamos que, por el contrario, al pasado, la nueva patria -la correísta- trae esperanza, trabajo, estabilidad, honestidad y justicia.

Rafael Correa ha sabido aprovechar las herramientas del populismo, y más precisamente del personalismo, para promover su ideología y posicionarla junto con su imagen. Los spots electorales de Correa apelan a la emotividad y a la nostalgia. Crean vínculos líder-pueblo, mediante discursos inclusivos, de referencias a un pasado común, pero también a sueños y un futuro común. Correa se presenta como el héroe que los ecuatorianos necesitan y, como tal, él se pone el país a sus hombros y genera un imaginario idílico que, aunque pueda parecer utópico, construye en el colectivo una idea sólida de esperanza.

Esta construcción de "patria" gira en torno a imaginarios colectivos. Esto se puede distinguir en dos instancias: una primera en la que Rafael Correa recurre a imaginarios ya establecidos para recordar, en un claro uso político del pasado, lo malo del pasado e identificar enemigos comunes de su gobierno y del pueblo; 
aquí, además, habla de la necesidad de recordarlos para impedir que se repitan. En una segunda instancia, pretende implantar unos nuevos, los suyos, en los que reitera que es él el hombre de la renovación política del país y, por lo tanto, el constructor de la nueva patria.

Aunque los discursos de Rafael Correa, así como las imágenes que aparecen en sus spots electorales pretendan ser cercanas y empáticas, éstas reafirman la hegemonía del gobierno, o más específicamente, del presidente. Al recaer toda la responsabilidad del proyecto político sobre un solo hombre, y sometido a su hipervisibilidad, se convierte Correa en el líder absoluto de la nueva patria. Además, con su constante oferta de una patria distinta y mejor, hace que recaiga sobre sus hombros la responsabilidad de mantener la esperanza del pueblo viva y de ser el comandante de los sueños comunes que él mismo se encargó de proponer.

Con todo lo expuesto, se puede entonces afirmar, que la intención del uso -y sobreutilización- del término "patria" en el material comunicacional de Rafael Correa tiene objetivos persuasivos de construcción identitaria, además de, claro está, electorales. Así, se puede identificar alrededor de su concepto, cómo se aplica toda la teoría de la propaganda como transmisora y constructora de imaginarios sociales que conllevan ideología y que se consolidan a través de sistemas de comunicación que existen como efecto y como causa de una hegemonía latente. 


\section{Bibliografía}

Asamblea Nacional del Ecuador. (2013). Ley Orgánica de Comunicación. Quito: Asamblea Nacional del Ecuador. Ayala Mora, E. (2002). Ecuador: patria de todos. Quito: Universidad Andina Simón Bolívar.

Barrios, I. (4 de octubre de 2016). VTB. Recuperado el 21 de marzo de 2017, "Chávez sigue impulsando la construcción de la patria de todos, recordó el jefe de estado": http://vtv.gob.ve/chavez-sigue-impulsando-la-construccion-dela-patria-de-todos-recordo-el-jefe-de-estado/

Cabrera, D. (2004). "Imaginario social, comunicación e identidad colectiva". Recuperado el 28 de febrero de 2017, de Imaginario social, comunicación e identidad colectiva: http://www.portalcomunicacion.com/dialeg/paper/pdf/ 143_cabrera.pdf

Campillo, A. (2013) "La propaganda electoral tradicional en la era de las nuevas tecnologías". Recuperado el 2 de junio de 2017, de XI Congreso Español de Ciencia Política y Administración: http://www.recp.es/uploads/files/modules/congress/11/papers/832.pdf

Captevila Gómez, A. (2004). Propaganda audiovisual: El discurso persuasivo : la estructura retórica de los spots electorales en televisión. Barcelona: Universitat Autonoma de Barcelona.

Castañeda, J. (2010). Lo que queda de la izquierda. Relatos de las izquierdas latinoamericanas. México: Editorial Taurus. Castells, M. (2001). Comunicación y poder. Madrid: Alianza Editorial.

Chaparro, M. (2015). Rafael Correa: Estrategia de politing en el siglo XXI. Caracas: Universidad de Zulia.

Concha, J. (1942). Eloy Alfaro: su vida y obra. Quito: Talleres Gráficos de Educación.

Correa, R. (2009). Ecuador: de banana republic a la no república. Bogotá: Nomos.

Donoso Pareja, M. (2004). Ecuador: identidad o esquizofrenia. Quito: Eskeletra.

Ferrandi, M. \& Fric, A. (2013). "El spot de Correa, un punto de densidad ideológica". Revista Question: perio.unlp.edu.ar/ojs/index.php/question/article/download/1836/1572

Floria, C. A. (1961). El "personalismo" político argentino. Estudios, 769-776.

Gifford, N. (2006). "Definiciones valorativas de la propaganda". En A. Pineda, Elementos para una teoría comunicacional de la propaganda. Sevilla: Alfar.

Gramsci, A. (2009). La política y el estado moderno. Barcelona : Público.

Granda, W. (2004). "El pasillo ecuatoriano: noción de idnetidad sonora". Quito: FLACSO. Recuperado de:

http://67.192.84.248:8080/handle/10469/2237\#.WRlySFIrx-U.

Herman, E., Said, E., \& Chomsky, N. (2009). Los guardianes de la libertad. Barcelona: Crítica.

Herreros, Mario. (1989) Teoría y técnica de la propaganda electoral. Barcelona: La Retrobrada

Huici, A. (1996). Estrategias de la persuasión. Mito y propaganda política. Sevilla: Alfar.

Laclau, E., \& Mouffe, C. (1987). Hegemonía y estrategia socialista: hacia una radicalización de la democracia. Madrid: Siglo Veintuno.

Laclau, E. (2005). La razón populista. Buenos Aires: FCE.

Morales López, E. (2012) "El discurso político de Rafael Correa". Revista Tonos: http://ruc.udc.es/dspace/handle/2183/9051. 
PAIS, C. A. (2009). Spot oficial Rafael Correa elecciones 2009 [Película]. Ecuador.

PAIS, C. A. (2013). La bicicleta [Película]. Ecuador.

Pineda, A. (2007). Elementos para una teoría comunicacional de la propaganda. Sevilla: Universidad de Sevilla.

Pizarroso Quintero, A. (1990). Historia de la propaganda. Madrid: Eudema.

Pizarroso Quintero, A. (1991). La guerra de las mentiras: información, propaganda y guerra psicológica en el conflicto del Golfo. Madrid: Eudema.

Pizarroso Quintero, A. (1993). Historia de la propaganda: notas para un estudio de la propaganda política y de guerra. Madrid: Eudema.

Rivera Costales, J. (2014) "Rafael Correa y las elecciones 2006. Inicios del Marketing y Comunicación política digital en Ecuador". Revista de comunicación latinoamericana Chasqui,116-123.

Rúas-Araujo, J et al. (2017) "Comunicación, lenguaje y política: Análisis de los discursos institucionales del presidente de Ecuador, Rafael Correa (2007-2015)". Revista razón y palabra. Recuperado de: http://revistarazonypalabra.org/index.php/ryp/article/view/846

Santander, P. (2011). "Por qué" y coómo hacer Análisis de Discurso". Cinta moebio. Recuperado de: www.moebio.uchile.cl/41/santander.html

Santos Rodríguez, E. (2012) Dimensión axiológica del socialismo del siglo XXI. Madrid: EAE

Sartori, G. (1998). Homo videns. Madrid: Taurus.

Soler, P. (2011). "Investigación cualitativa". En L. Vilches, La investigación en comunicación (págs. 189-237). Barcelona: Gedisa.

Torres, W. (2010). Estrategias políticas: cómo ganar elecciones. La Paz: Kipus.

Traverso, M. (1998). La identidad nacional en Ecuador. Un acercamiento psicosocial a la construcción nacional. Quito: AbyaYala

Van Dijk, T. (2009). Discurso y poder. Barcelona: Gedisa.

Vázquez-Liñán, M., \& Leetoy, S. (2016). Memoria histórica y propaganda. Una aproximación teórica al estudio comunicacional de la memoria. Nueva época (26), 71-94.

Viguera, A. (jul-sep de 1993). "Populismo y neopopulismo en América Latina". Revista mexicana de sociología , 49-66. Velázquez, T. (2011). "Las técnicas del análisis socio-semiótico". En L. Vilches, La investigación en comunicación (págs. 237-266). Barcelona: Gedisa. 